\title{
Selective Photocatalytic Oxidation of Steroid Estrogens in the Presence of Copollutants in the Sanitary Fraction of Domestic Sewage
}

\author{
Tatyana Karpova, Sergei Preis, and Juha Kallas \\ Department of Chemical Technology, Lappeenranta University of Technology, P.O. Box 20, 53851 Lappeenranta, Finland
}

Received 21 February 2007; Revised 22 May 2007; Accepted 5 June 2007

Recommended by Leonardo Palmisano

The photocatalytic oxidation (PCO) of the steroid estrogens (SEs), $\beta$-estradiol, and $17 \alpha$-ethynylestradiol, competitive with some constituent compounds of the sanitary fraction of domestic sewage, was studied. The copollutants, urea, and saccharose, present in concentrations exceeding those of the SEs by a factor of a hundred to thousands, appeared to exert a weaker influence to the photocatalytic degradation of the SEs than was expected. The removal of the SEs from diluted urine proceeded, selectively, demonstrating the potential of PCO in the treatment of the separate sanitary fraction of domestic sewage.

Copyright (C) 2007 Tatyana Karpova et al. This is an open access article distributed under the Creative Commons Attribution License, which permits unrestricted use, distribution, and reproduction in any medium, provided the original work is properly cited.

\section{INTRODUCTION}

In recent years, the observation of hermaphrodite fish in sewage treatment plant (STP) lagoons, reproductive abnormalities in reptiles, and decreased fertility of fish, mammals, and birds has made the question of the pollution of the aquatic environment with endocrine disrupting compounds (EDCs) one of great concern. These substances can interact with and disrupt the endocrine systems of living organisms. For humans, EDCs affect the male reproductive tract, both male and female fertilities, the central nervous system, and may cause several types of cancers [1]. Along with other EDCs, steroid estrogens (SEs) are believed to be major contributors to the observed estrogenic effects $[2,3]$. Steroid estrogens are already potent at the fraction of $n g \mathrm{~L}^{-1}$ concentrations, while most other EDCs are active at the $\mu \mathrm{g} \mathrm{L} \mathrm{L}^{-1}$ level [2].

The main source of SEs in domestic sewage is human waste that contains natural and also synthetic SEs originating from pharmaceuticals such as birth control pills and hormone replacement therapy. The SEs entering the STP in less active conjugated forms $[4,5]$ are, however, transferred in domestic sewage into the more potent active forms, presumably due to the presence of enzymes produced by faecal bacteria E. Coli [6]. Steroid estrogens have been detected in various concentrations in the discharge waters of STPs across
Europe $[3,7,8]$, depending on the type of STP process used, the density of population in the area, and various other factors. These data indicate that the inadequate removal of SEs in conventional STPs can lead to the penetration of these pollutants to the potable water. Various suggestions for improvements such as the increased size of sewage treatment tanks to prolong biodegradation or the removal of SEs with increased sludge concentration have not provided a solution to the problem $[8,9]$. An effective and economical treatment technique able to eliminate SEs from sewage is thus needed.

Several treatment strategies to eliminate SEs from aqueous media have been studied, all showing certain characteristic drawbacks. Simple redistribution of SEs between aqueous and solid phases by separation methods does not allow safe and complete elimination of SEs; further safe handling of the separated SEs is necessary [10]. Advanced oxidation processes such as ozone applications are able to remove SEs, although residual estrogenic activity at doses of ozone normally applied in potable water treatment has been observed [11]. Photocatalytic oxidation (PCO) has been confirmed to effectively eliminate SEs without the formation of estrogenic intermediates and is considered a potential approach [12-14].

In PCO, the excitation of a photocatalyst occurs as a result of the absorption of UV radiation at a wavelength sufficient to displace electrons from the valence band; for 


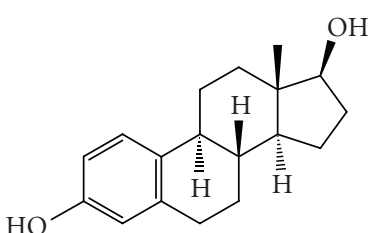

(a)

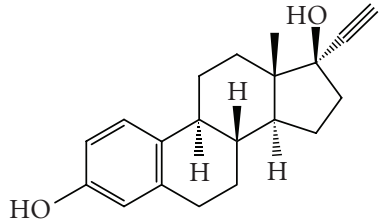

(b)
Figure 1: Molecular structures of E2 (a) and EE2 (b).

titanium dioxide, this is below $387.5 \mathrm{~nm}$. The PCO often proceeds via adsorption of the pollutant on the surface of the catalyst, followed by direct subtraction of the pollutant's electrons, that is, oxidation, with positively charged holes. Another possible way is oxidation with $\mathrm{OH}$-radicals that takes place at the catalyst surface or in its vicinity [15]. Both reactions may proceed simultaneously, and which mechanism dominates depend on the chemical and adsorption properties of the pollutant.

The elimination of SEs at the stage of the collection and separate treatment of the sanitary fraction of domestic sewage may appear beneficial compared to the treatment of large volumes of biologically treated municipal wastewaters. Sanitary sewage represents a complex mixture of organic and inorganic substances and the concentrations of copollutants are much higher than those of SEs and their presence may decrease the PCO rate of SEs. Thus, the objective of the present research was to establish the possibility of selective PCO of SEs in the presence of possible copollutants. Boeije et al. [16] have reconstituted a synthetic sanitary fraction of domestic sewage based on an extensive literature analysis, indicating urea and potato starch as the most common copollutants. However, chromatographic analysis in the presence of potato starch may be problematic due to clogging of chromatography columns. Therefore, the authors have chosen saccharose as a completely water-soluble starch replacement. To approximate the research results obtained in experiments with synthetic solutions of urea and saccharose to more realistic conditions, the authors studied the PCO of SEs in the presence of human urine.

\section{EXPERIMENTAL}

\subsection{Material}

Natural $\beta$-estradiol (E2) and synthetic $17 \alpha$-ethynylestradiol (EE2) were chosen as target SEs (Figure 1). To prepare the aqueous solution of SEs, they are usually dissolved first in an organic solvent due to their hydrophobic character. However, this can affect the experimental results, as the solvent acts, as an additional copollutant and can interfere with the PCO of the SEs. In a previous research, the authors used ethanol as an organic solvent for the preparation of the stock solution of SEs. It was observed, however, that ethanol as an $\mathrm{OH}$ radical scavenger competes with SEs for adsorption sites, interfering with the PCO of SEs [17]. In the present research, the SEs, which contain phenolic moieties, were successfully dissolved in water with a strongly alkaline reaction $(\mathrm{pH} 12.4)$ making the stock solutions free of the organic solvent. These stock solutions were constantly stirred in a hermetically sealed flask to avoid recrystallization of the SEs. The solutions with the required concentrations for the experiments were prepared by dilution of the stock solution with Milli-Q water under stirring for 30 minutes. The initial concentration of the PCOtreated solutions was around $500 \mu \mathrm{g} \mathrm{L}^{-1}$. All the PCO experiments were conducted at a room temperature of $23 \pm 2^{\circ} \mathrm{C}$. The $\mathrm{pH}$ value was adjusted with sulphuric acid or sodium hydroxide.

Titanium dioxide $\left(\mathrm{TiO}_{2}\right.$, Degussa P25) under near-UV irradiation was used as a photocatalyst. If not otherwise specified, its concentration in the PCO-treated suspensions was $10 \mathrm{mg} \mathrm{L}^{-1}$ as was thoroughly selected in previous studies [14]. This concentration of photocatalyst allows observation of the adsorption and oxidation results within the measurable SE concentration range: higher concentrations of $\mathrm{TiO}_{2}$ result in complete adsorption and rapid elimination of SEs from the solution. Centrifugation at 10,000 rpm was applied to separate the $\mathrm{TiO}_{2}$ from the samples before the analysis.

The copollutants were added to the solutions to be treated simultaneously with the SEs. Urea and saccharose, dried at $105^{\circ} \mathrm{C}$, in concentrations, respectively, of 75 and $50 \mathrm{mg} \mathrm{L}^{-1}$, broadly reflecting normal values in domestic sewage [16], were used in the experiments. The urine-water ratio was chosen from the average human excretion of 0.06 to $0.27 \mathrm{~L}$ of urine per each use to a dual flush system toilet utility of 3 to $6 \mathrm{~L}$ of water per flush. Both the maximum of $90 \mathrm{~mL} \mathrm{~L}^{-1}$ and minimum of $10 \mathrm{~mL} \mathrm{~L}^{-1}$ concentrations of urine in water were tested for SEs removal. Diluted urine did not show a noticeable UV-absorption at $365 \mathrm{~nm}$.

\subsection{Methods}

The PCO experiments were performed in $0.25 \mathrm{~L}$ capacity thermostatted batch glass reactors with an inner diameter of $100 \mathrm{~mm}$ supplied with a magnetic stirrer. The agitation intensity was maintained with a standard $25 \mathrm{~mm}$ Teflon stirrer at $300 \mathrm{rpm}$. A $365 \mathrm{~nm}$ UV-lamp (Sylvania F15W) was positioned horizontally over the reactor; the irradiance was about $1.1 \mathrm{~mW} \mathrm{~cm} \mathrm{~cm}^{-2}$ measured by UVX radiometer (UVX, USA). All PCO experiments were compared with reference samples treated under identical conditions except UV-radiation.

The adsorption experiments with the SEs and urea under various $\mathrm{pH}$ conditions were performed in $0.50 \mathrm{~L}$ capacity flasks, where the solutions were mixed with $\mathrm{TiO}_{2}$ at a stirring frequency of $900 \mathrm{rpm}$ for 24 hours at $25^{\circ} \mathrm{C}$. Each flask was handled separately as a single-point sample. The equilibrium concentration of compounds adsorbed on the surface of the catalyst $q, \mathrm{mg} \mathrm{g}^{-1} \mathrm{TiO}_{2}$, was calculated from the mass balance of the sample. The experiments to determine the adsorption properties of saccharose from the solution containing $250 \mathrm{mg} \mathrm{L}^{-1}$ of saccharose on $1 \mathrm{~g} \mathrm{~L}^{-1}$ of $\mathrm{TiO}_{2}$ were performed for 1 hour in a similar manner. 


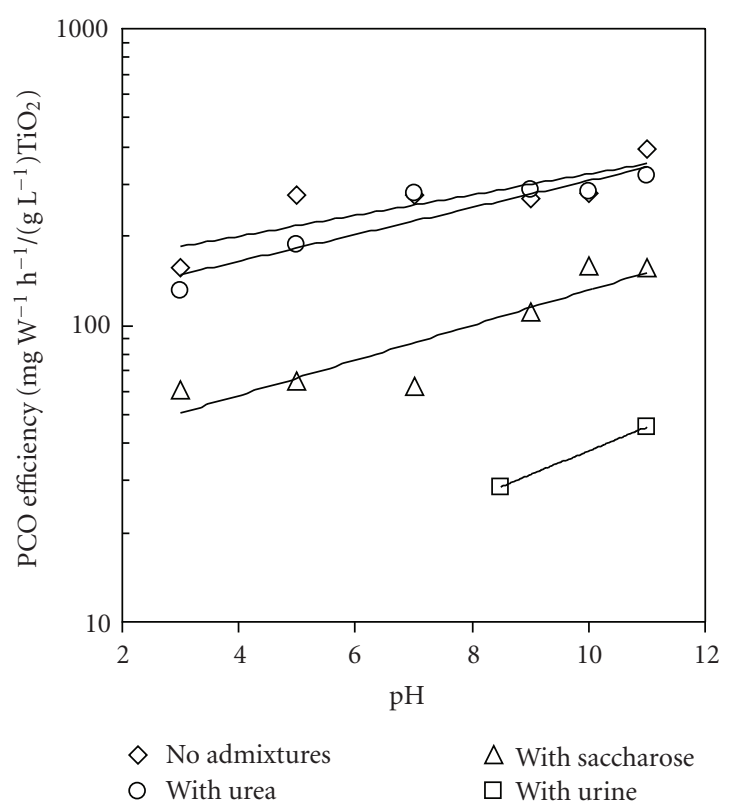

(a)

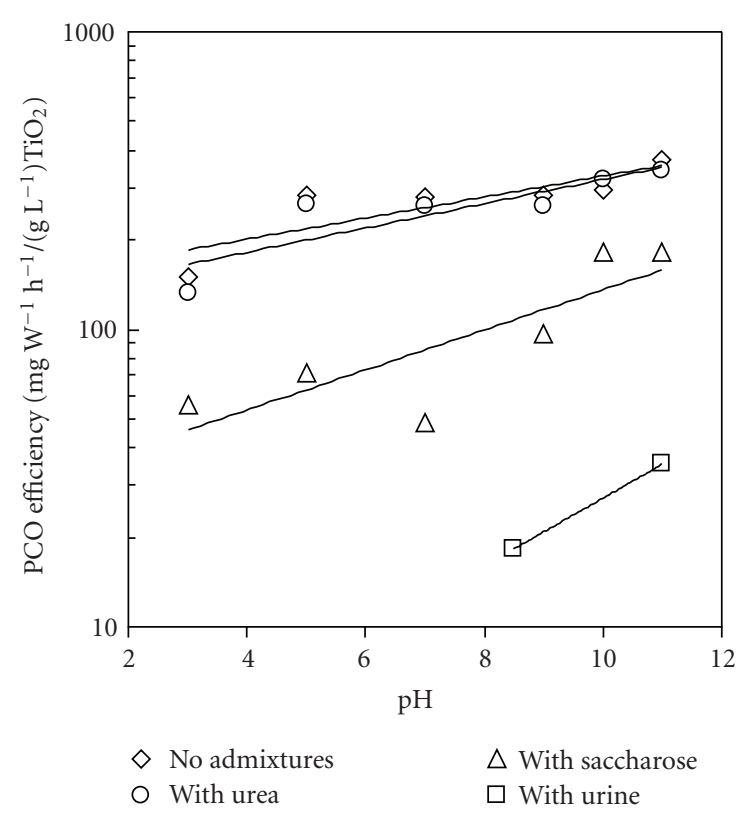

(b)

Figure 2: The dependence of the PCO efficiency of E2 (a) and EE2 (b) pH: treatment time 15 minutes and $10 \mathrm{mg} \mathrm{L}^{-1} \mathrm{TiO}_{2}$ except urine-120 minutes and $1 \mathrm{~g} \mathrm{~L}^{-1}$, respectively.

\subsection{Analysis}

The concentrations of SEs were measured by means of HPLC with a UV-detector using a $150 \mathrm{~mm}$ ZORBAX Eclipse XDB-C18 column (Agilent) at the wavelength $278 \mathrm{~nm}$, mobile phase was acetonitrile-water $(1: 1)$ at a flow rate of $1.0 \mathrm{~mL} \mathrm{~min}{ }^{-1}$. The urea concentrations were measured according to the method described in [18], developed in [19], and modified in the present research. The $10 \mathrm{~mL}$ test tubes were filled with $3.5 \mathrm{~mL}$ of the 35 -fold diluted sample, $0.25 \mathrm{~mL}$ of the reagent $\mathrm{A}$, and stirred. The $0.8 \mathrm{~mL}$ of reagent $\mathrm{B}$ was then immediately added with subsequent stirring. The test tubes were stored at room temperature for 72 hours in the dark. The light absorbance was then measured at $520 \mathrm{~nm}$. Reagent A was made of $8.5 \mathrm{~g}$ diacetylmonoxime in $250 \mathrm{~mL}$ of water together with $10 \mathrm{~mL}$ of solution containing $0.95 \mathrm{~g}$ of thiosemicarbazide in $100 \mathrm{~mL}$ of water (all chemicals SigmaAldrich). Reagent B was prepared by dissolving $300 \mathrm{~mL}$ of concentrated sulphuric acid in $535 \mathrm{~mL}$ of water with the addition of $0.5 \mathrm{~mL}$ of a solution containing $0.15 \mathrm{~g}$ of ferric chloride in $10 \mathrm{~mL}$ of water.

Chemical oxygen demand (COD), measured by a standard procedure [20], and total organic carbon (TOC) were determined after PCO and adsorption of saccharose. COD was also measured to observe the changes in the concentration of urine. The TOC analyses were carried out using the TOC analyzer Shimadzu 5050-A.

\section{RESULTS AND DISCUSSION}

The PCO was characterized by the process efficiency relative to the $\mathrm{TiO}_{2}$ concentration calculated as the decrease in the concentration of the SE divided by the amount of energy reaching the surface of the sample and by the concentration of the catalyst used:

$$
E=\frac{\Delta c \cdot V \cdot 1000}{I \cdot s \cdot t \cdot m}
$$

$E\left(\mathrm{mg} \mathrm{W}^{-1} \mathrm{~h}^{-1}\right.$ per $\left.\mathrm{g} \mathrm{L}^{-1} \mathrm{TiO}_{2}\right)$ represents the PCO process efficiency relative to the catalyst concentration; $\Delta c\left(\mu \mathrm{g} \mathrm{L}^{-1}\right)-$ decrease in the target compound concentration; $V(\mathrm{~L})-$ volume of treated sample; $I\left(\mathrm{~mW} \mathrm{~cm}^{-2}\right)$-irradiation intensity; $s\left(\mathrm{~cm}^{2}\right)$ - solution irradiated surface area; $t(\mathrm{~h})$ treatment time; $m\left(\mathrm{~g} \mathrm{~L}^{-1}\right)$ - concentration of $\mathrm{TiO}_{2}$.

The dependence of the PCO efficiency of the SEs, related to the $\mathrm{TiO}_{2}$ concentration, on $\mathrm{pH}$ with and without copollutants added can be seen in Figure 2. One can see that the strongly alkaline medium was the most efficient for the PCO of both natural and synthetic SEs despite the presence of admixtures.

The adsorption characteristics of the SEs on $\mathrm{TiO}_{2}$ were carefully studied for various $\mathrm{pH}$ values (Figure 3 ). The results indicate that the adsorption of SEs increases with the increasing $\mathrm{pH}$ making the strongly alkaline medium beneficial.

The PCO efficiency and adsorption consistently improve with the increasing $\mathrm{pH}$ indicating that the $\mathrm{PCO}$ rate is determined by the adsorption properties of the SEs on the $\mathrm{TiO}_{2}$ surface.

\subsection{The influence of urea}

Little influence of urea on the PCO efficiency of both SEs was observed; the beneficial character of the increasing $\mathrm{pH}$ remained (Figure 2). The observed indifference of the PCO 


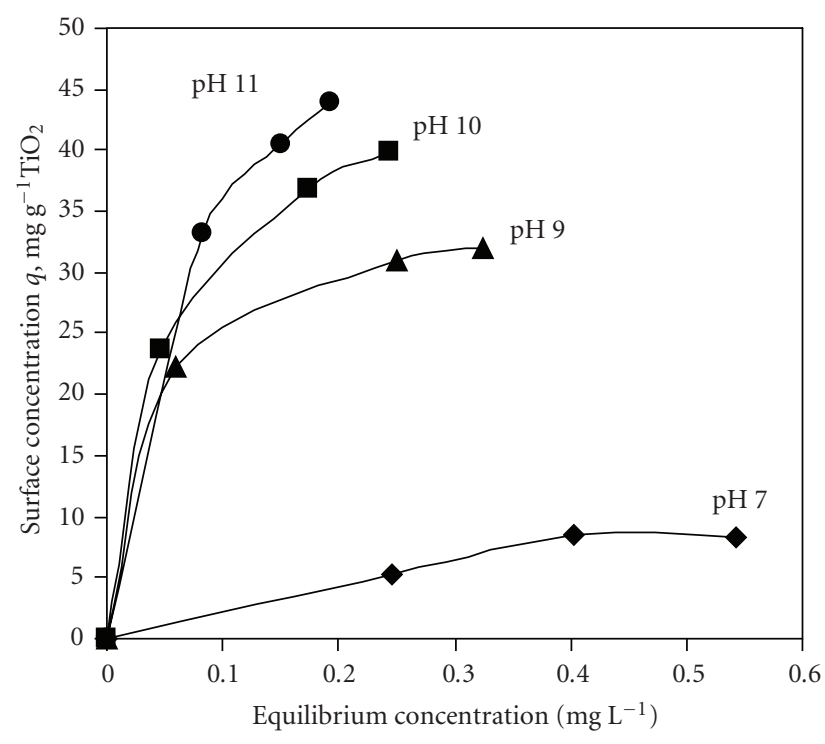

(a)

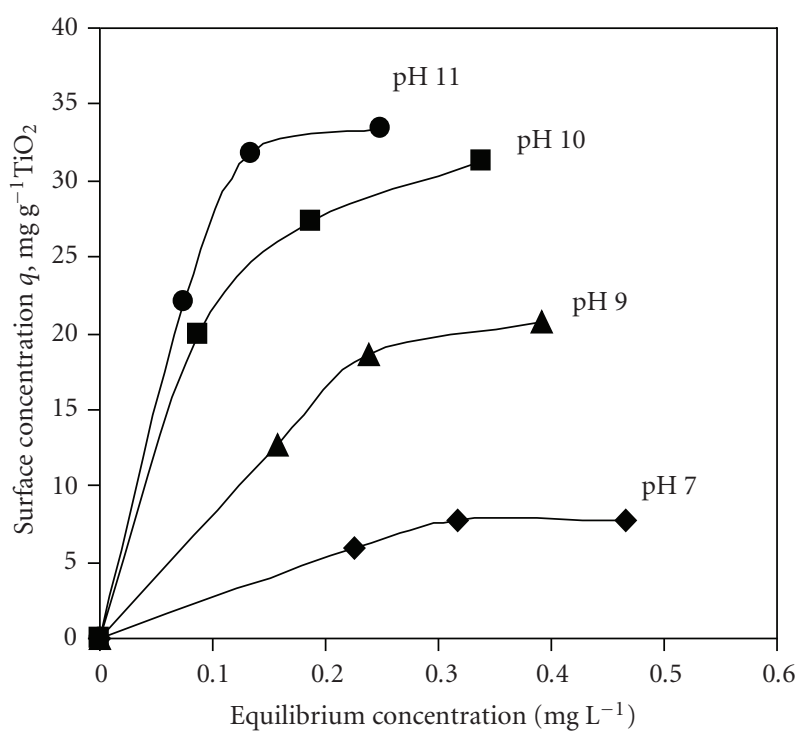

(b)

Figure 3: Adsorption isotherms for E2 (a) and EE2 (b) on $\mathrm{TiO}_{2}$ catalyst surface at different pH values without co-pollutant.

of the SEs towards the presence of urea may be explained by the poor adsorption of urea at the $\mathrm{TiO}_{2}$ surface. No detectable oxidation of urea was found within 2 hours of PCO at any of the $\mathrm{pH}$ values tested at the $\mathrm{TiO}_{2}$ concentration of $10 \mathrm{mg} \mathrm{L}^{-1}$. No changes in urea concentration were observed within the experimental time even with the catalyst concentration increase to $1 \mathrm{~g} \mathrm{~L}^{-1}$.

Figure 4 shows that the presence of urea seemed to have an insignificant effect on the EE2 adsorption on $\mathrm{TiO}_{2}$. The effect of urea on E2 adsorption was more evident: the adsorption in presence of urea decreased although it was still of the same order of magnitude as without urea. The dependence of adsorption on $\mathrm{pH}$ remained similar to the previously obtained one (Figure 3), which confirmed that the PCO of the SEs depends on the adsorption properties. The difference in behavior of the two SEs may be explained by the difference in the hydrophilic properties of the two molecules: the presence of urea may have a stronger impact on the adsorption of the more hydrophilic E2 molecule than the more hydrophobic EE2. The slope of the lines of the logarithmic dependence of the surface concentrations on $\mathrm{pH}$ was somewhat greater in the presence of urea for both SEs, which indicates a higher sensitivity of adsorption towards $\mathrm{pH}$ in the presence of the admixture.

\subsection{The influence of saccharose}

The presence of saccharose essentially hindered the PCO efficiency of SEs for the entire $\mathrm{pH}$ range (Figure 2). Although the strongly alkaline medium remained the most efficient for the process, the dependence on $\mathrm{pH}$ appears to differ somewhat from that without copollutants: the PCO rate in strongly acidic media at $\mathrm{pH} 3$, was slightly higher than in neutral

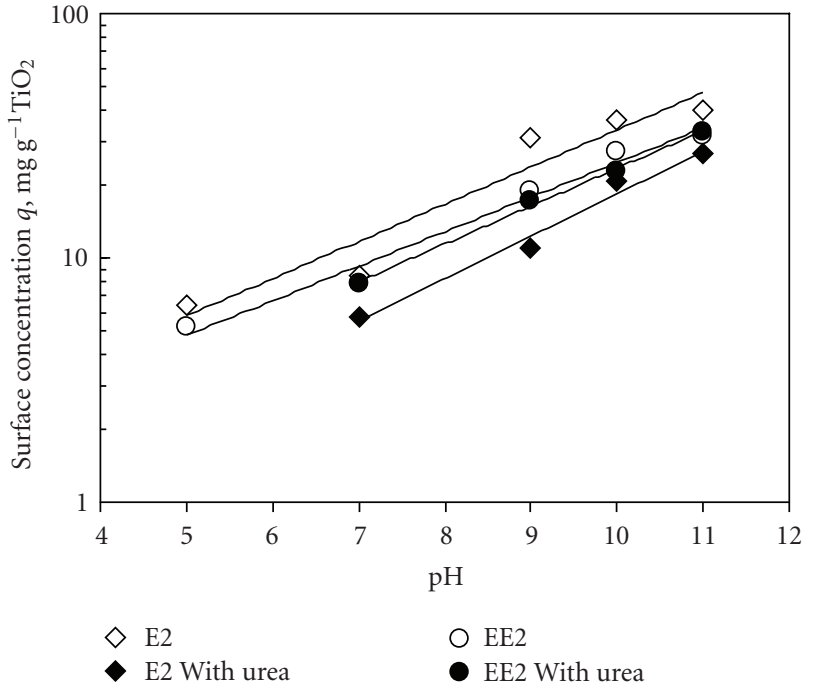

FIGURE 4: The SEs equilibrium surface concentrations on $\mathrm{TiO}_{2}$ versus $\mathrm{pH}$ with and without the presence of urea $\left(75 \mathrm{mg} \mathrm{L}^{-1}\right)$.

or slightly acidic ones. Since the adsorption is a prerequisite of PCO, the adsorptive properties of saccharose on $\mathrm{TiO}_{2}$ were also studied to try to explain this deviation. The equilibrium surface concentrations versus $\mathrm{pH}$ for saccharose are presented in Figure 5. The best adsorption, although rather poor, was observed at $\mathrm{pH} 5$, explained by the proximity to the zero charge point of $\mathrm{TiO}_{2}$. At $\mathrm{pH} 3$, the adsorption was significantly smaller, which accounts for the better adsorption and PCO of SEs at this point. The difficulties in maintaining $\mathrm{pH} 7$ in the PCO experiments may explain why the PCO 


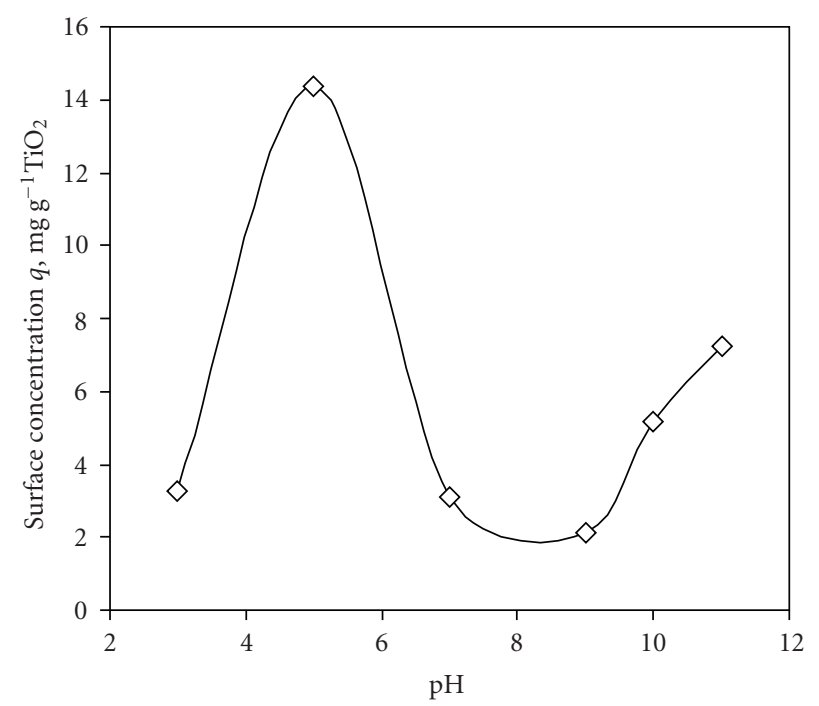

FIgURE 5: Saccharose equilibrium surface concentration on $\mathrm{TiO}_{2}$ catalyst versus $\mathrm{pH}$ : initial concentration of saccharose $250 \mathrm{mg} \mathrm{L}^{-1}$.

rates were similar at $\mathrm{pH} 5$ and 7. PCO of an aqueous solution of $50 \mathrm{mg} \mathrm{L}^{-1}$ of saccharose with $10 \mathrm{mg} \mathrm{L}^{-1}$ of $\mathrm{TiO}_{2}$ was carried out to gain the better understanding of the interactions between the SEs and saccharose. The results showed no visible degradation of COD or TOC within 4 hours. Both the catalyst and pollutant concentrations were then increased to $0.5 \mathrm{~g} \mathrm{~L}^{-1}$ and $150 \mathrm{mg} \mathrm{L}^{-1}$, respectively, but only minor, around $10 \%$, oxidation of saccharose was observed at $\mathrm{pH} 11$ in 2 hours of PCO.

One can see that poor saccharose adsorption and, therefore, PCO cannot explain the interference exhibited by the saccharose in SEs' oxidation. The reduction in the PCO efficiency of SEs may thus be explained by radical scavenging properties of saccharose.

\subsection{The influence of urine}

The effect of urine as a copollutant on the PCO of SEs was studied under two $\mathrm{pH}$ conditions: $\mathrm{pH} 11$ (the most beneficial for the process) and $\mathrm{pH} 8.5$ (natural $\mathrm{pH}$ of urine diluted with the Milli-Q water). The photocatalyst concentration of $1 \mathrm{~g} \mathrm{~L}^{-1}$ was applied. The degradation of oxidisible substances in urine was tracked by the decrease in COD. The substances seemed not to undergo significant oxidation under the experimental conditions: the COD of the urine sample diluted 100-fold was initially around $200 \mathrm{mg} \mathrm{O}_{2} \mathrm{~L}^{-1}$ and decreased by only 20 to $40 \mathrm{mg} \mathrm{O}_{2} \mathrm{~L}^{-1}$ at $\mathrm{pH} 8.5$ while at $\mathrm{pH} 11$ remained practically unchanged within 2 hours. A more concentrated urine solution had an initial COD of $1400 \mathrm{mg} \mathrm{O}_{2} \mathrm{~L}^{-1}$ and the COD did not change with PCO under the same conditions.

Initially, a urine solution with COD of $1400 \mathrm{mg} \mathrm{O}_{2} \mathrm{~L}^{-1}$ was used in the experiments. Besides the negligible decrease in COD, no significant oxidation of SEs was observed within
2 hours of PCO. Presumably, the constituent compounds of urine, being resistant towards PCO, occupied the adsorption sites of the catalyst and did not allow the SEs to adsorb and oxidize under competitive adsorption conditions. The PCO degradation of SEs was clearly exhibited with the more diluted urine concentration with an initial COD of $200 \mathrm{mg} \mathrm{O}_{2} \mathrm{~L}^{-1}$; the target compounds were eliminated dependent on $\mathrm{pH}$ as in Figure 2. Complete oxidation of E2 and 95\% oxidation of EE2 were observed at pH 11 in the 2-hour experiment; around $75 \%$ of both SEs were oxidized under natural $\mathrm{pH}$ conditions. This result was observed with a negligible decrease in COD, which indicates that the SEs can be degraded in a selective manner by PCO in a strong alkaline medium. Greater concentrations of copollutants from urine may, however, dramatically slow down the PCO of the SEs.

\subsection{The kinetic studies}

The PCO of various organic compounds using UVilluminated $\mathrm{TiO}_{2}$ can be formally described by the monomolecular Langmuir-Hinshelwood kinetic model

$$
-\frac{d c}{d t}=\frac{k \cdot K \cdot c}{1+K \cdot c},
$$

$d c / d t$ is the rate of oxidation, $k$ is the apparent reaction rate constant, $K$-the adsorption coefficient of the compound to be oxidized, and $c$ is its concentration at time $t$. If the concentration of the compound is very low, that is, $K \cdot c \ll 1$, which is the case in this research, the Langmuir-Hinshelwood model can be simplified to a pseudo-first-order kinetic reaction

$$
-\frac{d c}{d t}=k^{\prime} \cdot c
$$

$k^{\prime}$ is the pseudo-first-order reaction rate constant $\left(k^{\prime}=k \cdot \mathrm{K}\right)$.

The results of the PCO experiments of SEs solutions with and without copollutants were plotted as time in minutes against $\ln \left(c / c_{0}\right)$, where $c_{0}$ represents the initial concentration of the SEs. The best fit line was drawn and the equation and correlation coefficient, $R^{2}$, were obtained. The plots demonstrated that the PCO of the SEs fitted well to the pseudo-firstorder equations, which is consistent with previously published results $[12,13]$. The rate constant $k^{\prime}$ was obtained from the slope and the initial rate was calculated by multiplying $k^{\prime}$ by $\mathcal{c}_{0}$. The half-life was then calculated. The results are presented in Table 1.

The data reveal that in the absence of copollutants the PCO of EE2 proceeded a little faster than that of E2, except for $\mathrm{pH} 11$ and $\mathrm{pH} 3$, where the rates are almost equal. This result is in agreement with the data of other authors: Coleman et al. [13] reported PCO rate values for acidic media ( $\mathrm{pH} \mathrm{3.5-4)} \mathrm{as} \mathrm{big} \mathrm{as} 0.522 \mu \mathrm{mol} \mathrm{dm}{ }^{-3} \mathrm{~min}^{-1}$ for E2 and $0.694 \mu \mathrm{mol} \mathrm{dm}{ }^{-3} \mathrm{~min}^{-1}$ for EE2, which, although exceeding the results given in Table 1 , are of the same order of magnitude. The difference is attributed to the significantly higher UV-light intensity used by Coleman et al. [13]. 
TABLE 1: Kinetic parameter value for PCO of SEs with and without copollutants.

\begin{tabular}{|c|c|c|c|c|c|c|c|c|c|c|c|}
\hline Substance & $\mathrm{pH}$ & $\begin{array}{c}k^{\prime} \\
\left(\min ^{-1}\right)\end{array}$ & $\begin{array}{c}\text { Rate } \\
\left(\mu \mathrm{mol} \mathrm{dm}{ }^{-3} \min ^{-1}\right)\end{array}$ & $\begin{array}{c}\text { Half-life } \\
(\min )\end{array}$ & $\mathrm{R}^{2}$ & Substance & $\mathrm{pH}$ & $\begin{array}{c}k^{\prime} \\
\left(\min ^{-1}\right)\end{array}$ & $\begin{array}{c}\text { Rate } \\
\left(\mu \mathrm{mol} \mathrm{dm} \mathrm{dm}^{-3} \mathrm{~min}^{-1}\right)\end{array}$ & $\begin{array}{c}\text { Half-life } \\
(\min )\end{array}$ & $\mathrm{R}^{2}$ \\
\hline \multirow{6}{*}{ E2 } & 11 & 0.254 & 0.528 & 2.8 & 0.995 & \multirow{6}{*}{ EE2 } & 11 & 0.295 & 0.519 & 2.4 & 1.000 \\
\hline & 10 & 0.091 & 0.190 & 7.4 & 0.995 & & 10 & 0.116 & 0.205 & 5.9 & 0.999 \\
\hline & 9 & 0.070 & 0.140 & 9.7 & 0.988 & & 9 & 0.107 & 0.188 & 6.5 & 1.000 \\
\hline & 7 & 0.068 & 0.132 & 10.4 & 0.984 & & 7 & 0.110 & 0.191 & 6.2 & 0.999 \\
\hline & 5 & 0.072 & 0.148 & 9.6 & 0.990 & & 5 & 0.107 & 0.184 & 6.5 & 0.999 \\
\hline & 3 & 0.034 & 0.070 & 20.2 & 0.998 & & 3 & 0.042 & 0.070 & 16.6 & 0.997 \\
\hline \multirow{6}{*}{ E2 with urea } & 11 & 0.263 & 0.441 & 2.6 & 1.000 & \multirow{6}{*}{ EE2 with urea } & 11 & 0.293 & 0.458 & 2.4 & 1.000 \\
\hline & 10 & 0.183 & 0.290 & 3.7 & 0.986 & & 10 & 0.241 & 0.378 & 2.9 & 1.000 \\
\hline & 9 & 1.176 & 0.290 & 3.9 & 0.990 & & 9 & 0.100 & 0.159 & 6.6 & 0.917 \\
\hline & 7 & 0.175 & 0.278 & 3.9 & 0.993 & & 7 & 0.094 & 0.138 & 7.2 & 0.978 \\
\hline & 5 & 0.068 & 0.116 & 10.1 & 0.987 & & 5 & 0.088 & 0.141 & 7.8 & 0.989 \\
\hline & 3 & 0.036 & 0.058 & 19.0 & 0.996 & & 3 & 0.032 & 0.048 & 21.2 & 0.997 \\
\hline \multirow{6}{*}{$\begin{array}{l}\text { E2 with } \\
\text { saccharose }\end{array}$} & 11 & 0.049 & 0.083 & 13.7 & 0.992 & \multirow{6}{*}{$\begin{array}{l}\text { EE2 with } \\
\text { saccharose }\end{array}$} & 11 & 0.058 & 0.091 & 11.88 & 0.996 \\
\hline & 10 & 0.036 & 0.061 & 19.0 & 0.984 & & 10 & 0.050 & 0.076 & 13.7 & 0.997 \\
\hline & 9 & 0.022 & 0.036 & 30.9 & 0.975 & & 9 & 0.018 & 0.031 & 36.3 & 0.975 \\
\hline & 7 & 0.011 & 0.019 & 58.8 & 0.989 & & 7 & 0.009 & 0.015 & 72.6 & 0.984 \\
\hline & 5 & 0.010 & 0.017 & 63.2 & 0.969 & & 5 & 0.011 & 0.017 & 60.1 & 0.983 \\
\hline & 3 & 0.016 & 0.027 & 42.2 & 0.997 & & 3 & 0.015 & 0.022 & 48.0 & 0.995 \\
\hline \multirow{2}{*}{$\begin{array}{l}\text { E2 with } \\
\text { urine }\end{array}$} & 11 & 0.021 & 0.039 & 31.8 & 0.883 & \multirow{2}{*}{$\begin{array}{l}\text { EE2 with } \\
\text { urine }\end{array}$} & 11 & 0.022 & 0.035 & 29.0 & 0.850 \\
\hline & 8.5 & 0.011 & 0.019 & 62.5 & 0.967 & & 8.5 & 0.012 & 0.019 & 60.3 & 0.979 \\
\hline
\end{tabular}

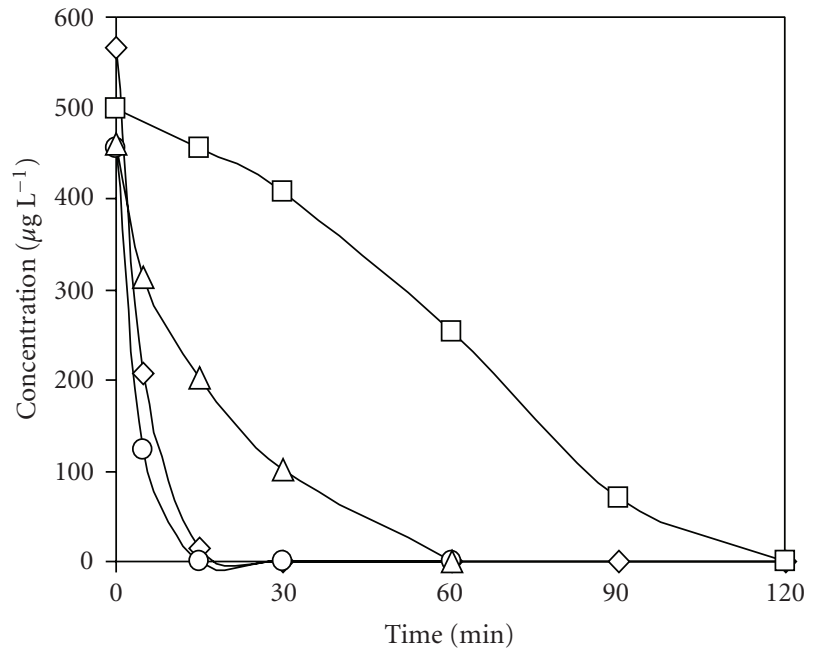

$\begin{array}{ll}\checkmark-\text { No admixtures } & - \text { With saccharose } \\ -\bigcirc-\text { With urea } & -\square-\text { With urine }\end{array}$

(a)

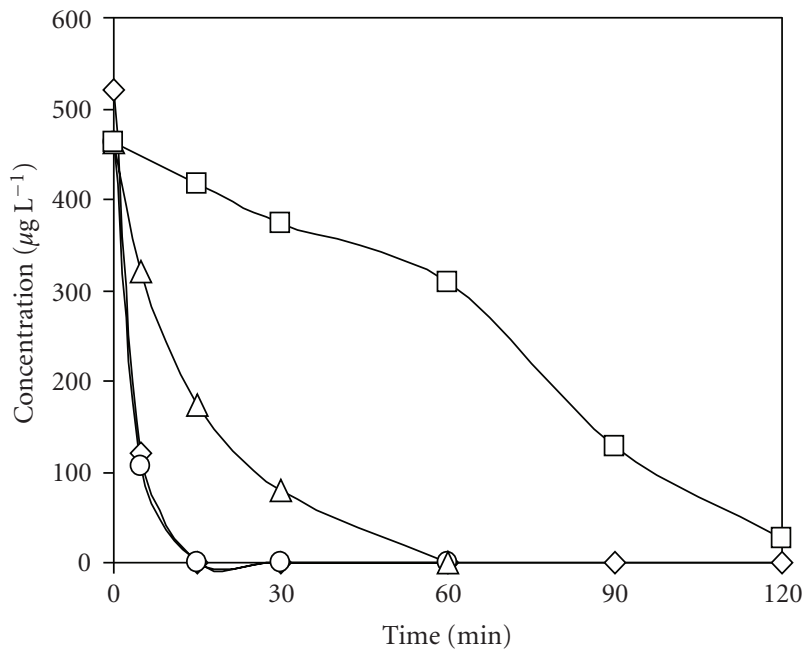

$\checkmark$ No admixtures $\quad-\checkmark$ With saccharose $-\mathrm{O}-$ With urea

(b)

FIgURe 6: The rate of PCO of E2 (a) and EE2 (b) at pH 11 under different admixture conditions: $75 \mathrm{mg} \mathrm{L}^{-1}$ of urea, $50 \mathrm{mg} \mathrm{L}^{-1}$ of saccharose, $10 \mathrm{~mL} \mathrm{~L}^{-1}$ of urine. 
In the presence of urea and saccharose, however, the rate of PCO of E2 was faster in neutral and strongly acidic media. No noticeable difference in the PCO rates of the SEs could be seen when urine was present as a copollutant. The results clearly indicate that despite the presence of copollutants, the PCO of the SEs exhibited the fastest rate under strongly alkaline media conditions. The impact of copollutants is illustrated in Figure 6, where the degradation curves of SEs are plotted for $\mathrm{pH} 11$, the most beneficial $\mathrm{pH}$ for the process, in the presence of the admixtures under consideration. The interference of the cpollutants was, nevertheless, far weaker in respect to the PCO of the SEs than could be expected from the hundred to thousands times higher concentration of the admixtures. This indicates the potential of PCO to be a selective oxidation method for the removal of SEs from wastewaters.

\section{CONCLUSIONS}

A strongly alkaline medium was found to be the most beneficial for the adsorption of SEs on the $\mathrm{TiO}_{2}$ photocatalyst, which explains the most efficient $\mathrm{PCO}$ at high $\mathrm{pH}$. The same result was observed also in the presence of urea, saccharose, and human urine.

The PCO of SEs was seen to be indifferent towards the presence of urea in concentrations commonly found in domestic sewage. Saccharose interferes with the PCO of the target compounds hindering the oxidation rate of SEs: saccharose, poorly adsorbed and oxidized photocatalytically itself, most likely acts as an $\mathrm{OH}$-radical scavenger. Urine significantly decreased the PCO rate of SEs at concentrations above $1: 100$. Nevertheless, the effect of the copollutants on the PCO of SEs is far weaker than could be expected from the concentrations of the admixtures, which are from one hundred to a few thousands times higher than that of the SEs. Although higher concentrations of copollutants can dramatically slow down the PCO of SEs, realistic concentrations of urea and saccharose characteristic for the sanitary fraction of domestic sewage allowed selective removal of SEs.

\section{ACKNOWLEDGMENTS}

The authors appreciate the financial support of the Graduate School in Chemical Engineering, Finland, and project 208134 of the Academy of Finland programme "Russia in flux." The efforts of Miss Adélia Luciana Barros Torres, graduate student from The University of Porto, Portugal, are acknowledged with gratitude.

\section{REFERENCES}

[1] J. J. Amaral Mendes, "The endocrine disrupters: a major medical challenge," Food and Chemical Toxicology, vol. 40, no. 6, pp. 781-788, 2002.

[2] C. Purdom, P. Hardiman, V. Bye, N. Eno, C. Tyler, and J. P. Sumpter, "Estrogenic effects of effluents from sewage treatment works," Chemistry and Ecology, vol. 8, no. 4, pp. 275-285, 1994.
[3] M. Pettersson, M. Adolfsson-Erici, J. Parkkonen, L. Förlin, and L. Asplund, "Fish bile used to detect estrogenic substances in treated sewage water," The Science of the Total Environment, vol. 366, no. 1, pp. 174-186, 2006.

[4] C. Desbrow, E. J. Routledge, G. C. Brighty, J. P. Sumpter, and M. Waldock, "Identification of estrogenic chemicals in STW effluent. 1. Chemical fractionation and in vitro biological screening," Environmental Science and Technology, vol. 32, no. 11, pp. 1549-1558, 1998.

[5] A. C. Johnson and J. P. Sumpter, "Removal of endocrinedisrupting chemicals in activated sludge treatment works," Environmental Science and Technology, vol. 35, no. 24, pp. 46974703, 2001.

[6] G. D'Ascenzo, A. Di Corcia, A. Gentili, et al., "Fate of natural estrogen conjugates in municipal sewage transport and treatment facilities," The Science of the Total Environment, vol. 302, no. 1-3, pp. 199-209, 2003.

[7] C. Baronti, R. Curini, G. D’Ascenzo, A. Di Corcia, A. Gentili, and R. Samperi, "Monitoring natural and synthetic estrogens at activated sludge sewage treatment plants and in a receiving river water," Environmental Science and Technology, vol. 34, no. 24, pp. 5059-5066, 2000.

[8] A. C. Johnson, H.-R. Aerni, A. Gerritsen, et al., "Comparing steroid estrogen, and nonylphenol content across a range of European sewage plants with different treatment and management practices," Water Research, vol. 39, no. 1, pp. 47-58, 2005.

[9] H. Andersen, H. Siegrist, B. Halling-Sørensen, and T. A. Ternes, "Fate of estrogens in a municipal sewage treatment plant," Environmental Science and Technology, vol. 37, no. 18, pp. 4021-4026, 2003.

[10] L. D. Nghiem, A. I. Schäfer, and T. D. Waite, "Adsorptive interactions between membranes and trace contaminants," Desalination, vol. 147, no. 1-3, pp. 269-274, 2002.

[11] M. M. Huber, T. A. Ternes, and U. von Gunten, "Removal of estrogenic activity and formation of oxidation products during ozonation of $17 \alpha$-ethinylestradiol," Environmental Science and Technology, vol. 38, no. 19, pp. 5177-5186, 2004.

[12] Y. Ohko, K.-I. Iuchi, C. Niwa, et al., " $17 \beta$-estradiol degradation by $\mathrm{TiO}_{2}$ photocatalysis as a means of reducing estrogenic activity," Environmental Science and Technology, vol. 36, no. 19, pp. 4175-4181, 2002.

[13] H. Coleman, M. Abdullah, B. Eggins, and F. Palmer, "Photocatalytic degradation of $17 \beta$-ostradiol, oestriol and $17 \alpha$ ethynyloestradiol in water monitored using fluorescence spectroscopy," Applied Catalysis B: Environmental, vol. 55, no. 1, pp. 23-30, 2005.

[14] T. Malygina, S. Preis, and J. Kallas, "The role of $\mathrm{pH}$ in aqueous photocatalytic oxidation of $\beta$-estradiol," International Journal of Photoenergy, vol. 7, no. 4, pp. 187-191, 2005.

[15] A. L. Linsebigler, G. Lu, and J. T. Yates Jr., "Photocatalysis on $\mathrm{TiO}_{2}$ surfaces: principles, mechanisms, and selected results," Chemical Reviews, vol. 95, no. 3, pp. 735-758, 1995.

[16] G. Boeije, R. Corstanje, A. Rottiers, and D. Schowanek, "Adaptation of the CAS test system and synthetic sewage for biological nutrient removal-part I: development of a new synthetic sewage," Chemosphere, vol. 38, no. 4, pp. 699-709, 1999.

[17] T. Karpova, A. L. Barros Torres, S. Preis, and J. Kallas, "Selective photocatalytic oxidation of steroid estrogens in the presence of saccharose and ethanol as co-pollutants," to appear in Environmental Chemistry Letters.

[18] P. Mulvenna and G. Savidge, "A modified manual method for the determination of urea in seawater using diacetylmonoxime reagent," Esturiane, Coastal and Shelf Science, vol. 34, no. 5, pp. 429-438, 1992. 
[19] L. Goeyens, N. Kindermans, M. Abu Yusuf, and M. Elskens, "A room temperature procedure for the manual determination of urea in seawater," Estuarine, Coastal and Shelf Science, vol. 47, no. 4, pp. 415-418, 1998.

[20] A. E. Greenberg, Ed., Standard Methods for the Examination of Water and Wastewater, American Public Health Association, Washington, DC, USA, 19th edition, 1995. 


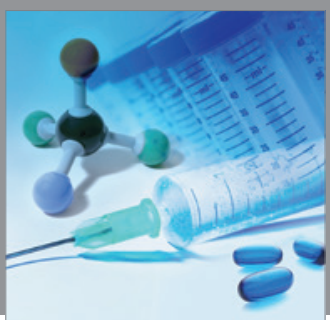

International Journal of

Medicinal Chemistry

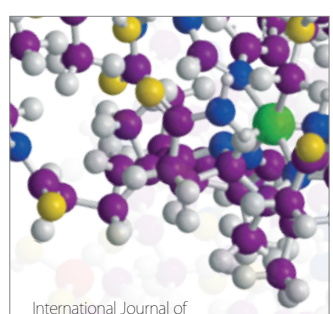

Carbohydrate Chemistry

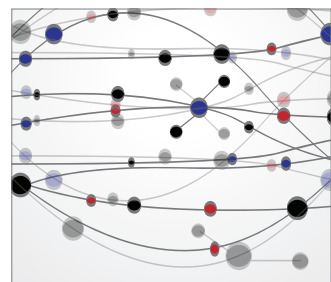

The Scientific World Journal
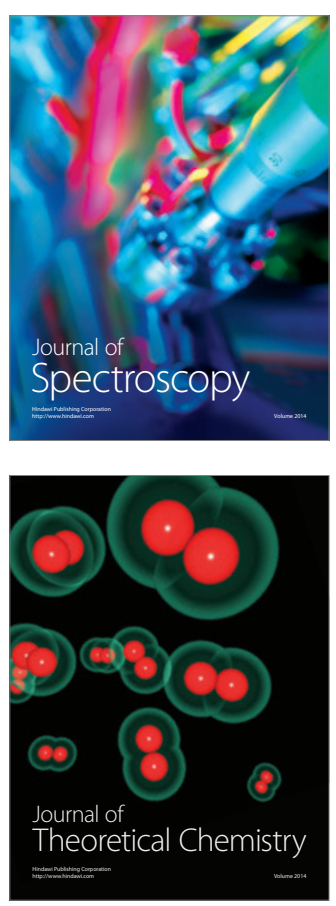
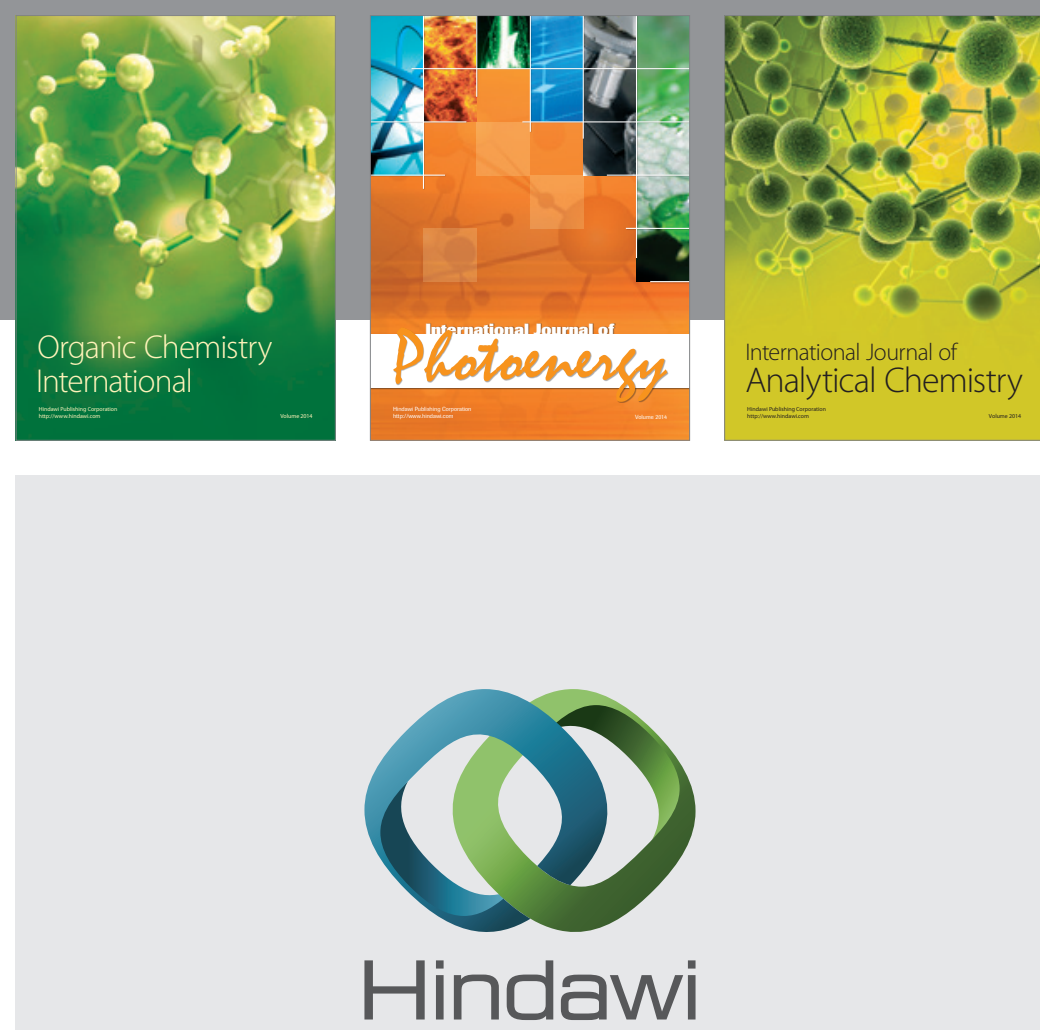

Submit your manuscripts at

http://www.hindawi.com
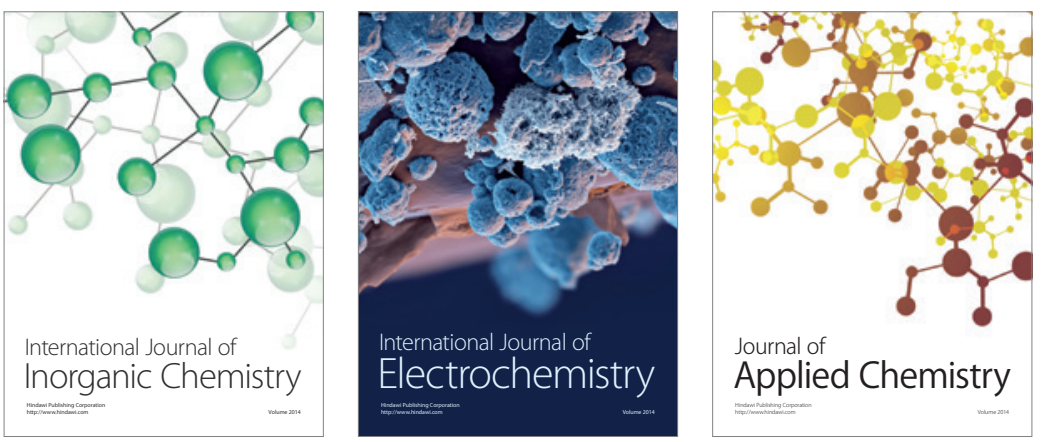

Journal of

Applied Chemistry
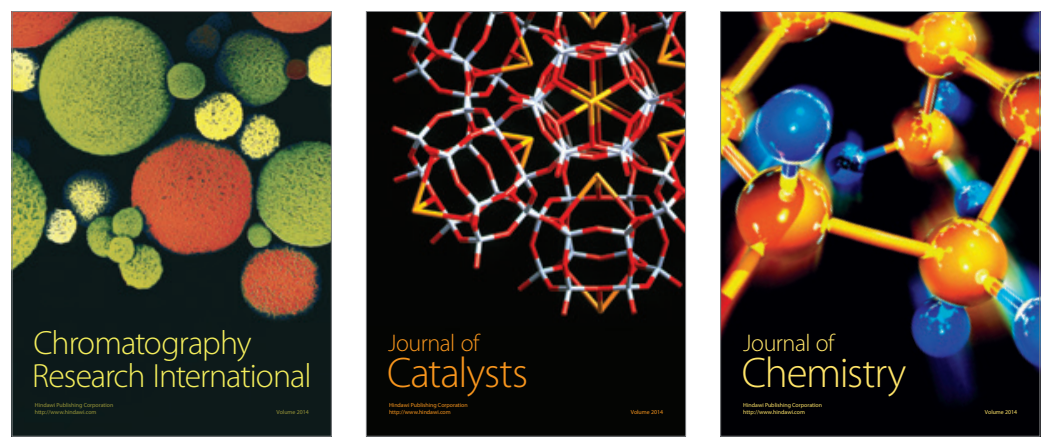
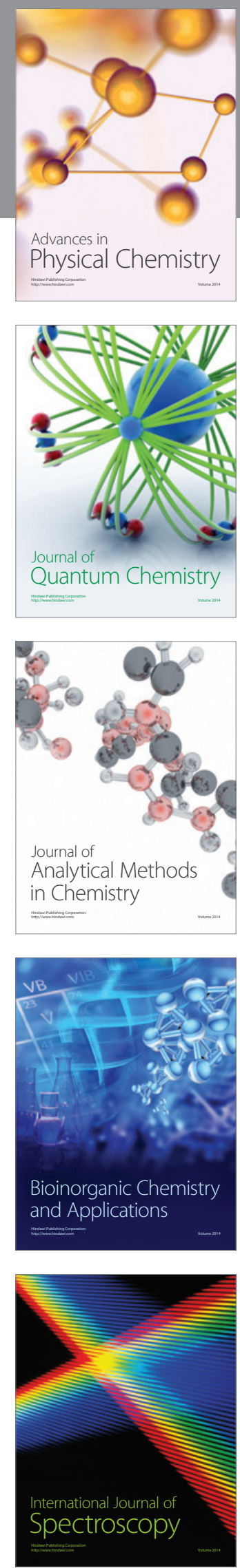